\title{
Monográfico: Música y Educación: Una mirada femenina
}

\section{Título en inglés}

\author{
Desirée García-Gil \\ desirega@ucm.es \\ Departamento de Didáctica de las Lenguas, Artes y Educación Física \\ Universidad Complutense de Madrid \\ Madrid, España \\ ORCID: http://orcid.org/0000-0002-0591-6873

$\begin{array}{r}\text { Consuelo Pérez-Colodrero } \\ \text { consuelopc@ ugr.es }\end{array}$
Departamento de Historia y Ciencias de la Música
Universidad de Granada
Granada, España

doi: 10.7203/LEEME.44.16208

Recibido: 04-12-2019 Aceptado: 04-12-2019. Contacto y correspondencia: Desirée García Gil, Departamento de Didáctica de las Lenguas, Artes y Educación Física Universidad Complutense de Madrid, Facultad de Educación, Avenida Rector Royo Villanova, s/n, 28040 Madrid. España.

Resulta evidente que cualquier experiencia musical transmite significados relacionados con el género, de tal suerte que, desde la creación a la percepción, pasando por la interpretación, el aprendizaje y la enseñanza, todos los procesos musicales producen ideologías y transmiten connotaciones derivadas de esta perspectiva. La exploración de las relaciones de género a través de música, no obstante, no irrumpió en la investigación hasta la década de 1970, particularmente en el ámbito anglosajón, donde un reducido pero relevante número de especialistas, generalmente activistas del Feminismo, introdujo esta novedosa categoría de estudio como complemento y oposición al tipo de aproximación que sobre el hecho musical se estaba realizando por aquel entonces. Así, el primer objeto de estudio de la nueva tendencia fue las historias de vida y la producción de compositoras que habían sido marginadas por la narrativa tradicional, como Hildegard von Bingen o Barbara Strozzi (Bowers y Tick, 1986; Briscoe, 1987), prestando especial atención tanto a las condiciones sociales en las que se desarrolló su actividad artística como al variado perfil de tareas, no exclusivamente compositivas -en algunos casos, también como docentes-, que desplegaron a lo largo de sus respectivas carreras.

Como consecuencia de este novedoso interés por el rol de la mujer en la música tanto occidental como no occidental (Herndon y Ziegler, 1991; Koskoff, 1987; Sugarman, 1997), se reconsideraron las categorías de género en la Música, las músicas populares-urbanas (McClary, 1991) o las populares-tradicionales (Carby, 1990; Dahl, 1984; Davis, 1998; Gaar, 1992; Gourse, 1995; Harrison, 1988; Placksin, 1982; Rose, 1994) y aplicándose paulatinamente a distintos géneros musicales, entre los que cabría mencionar la ópera (Blackmer y Smith, 1995; Koestenbaum, 1993; Morris, 1993) o las pequeñas piezas para piano (Kallberg, 1992). La renovación alcanzó, a la postre, a un amplio conjunto de disciplinas (Adler, 1885), como la Organología (Austern, 1989; Leppert, 1989), la Estética (Cusick, 1993), la Teoría (Maus, 1993; Straus, 1995) o la Educación Musical (Green, 1997). Se trata, por tanto, de una perspectiva de obligado conocimiento para cualquiera que se aproxime al hecho musical y a su investigación científica, se compartan o no sus premisas, directrices y resultados, en tanto que conforma una de las «más notables contribuciones [al arte sonoro] de los últimos treinta años del siglo XX» (McLary, 2001: s/p). Así, este número de LEEME recoge dos aportaciones que, en el ámbito de 
la Música y la Educación Musical, proponen indagar en el sentido indicado para los estudios de género.

El texto de los Drs. Carolina Bonastre y Roberto Nuevo ("El aprendizaje expresivo y las diferencias de género en la Educación Superior de Música") explora las diferencias de género en el campo de los procesos de enseñanza-aprendizaje de la música en su nivel superior. Así, partiendo de las diferencias a la hora de elegir un instrumento y a optar a las salidas laborales, su trabajo, de naturaleza cuantitativa, indaga en la orientación técnica y profesional de casi doscientos estudiantes españoles y británicos. Su investigación muestra cómo existen materias y profesiones musicales en las que la presencia masculina y femenina es similar —este es el caso de instrumentos como el piano, la guitarra o los integrados en la familia de la cuerda frotada, así como de ocupaciones vinculadas con la interpretación, la docencia, la investigación o la crítica musical- En cambio, en su estudio se aprecia cómo aún existe una clara desproporción en el estudio del canto — en el que las mujeres son mayoría - y en el ejercicio de profesiones vinculadas a la composición o la dirección orquestal —en el que abundan los hombres- Al tiempo, se evidencia cómo el empleo de las estrategias de aprendizaje es distinto y favorable a las féminas, en tanto que estas tienden al uso de metáforas e imágenes que, además, consideran un recurso efectivo en el aula. A la hora de entender y evaluar el conjunto de estos datos, la autora arguye razones de diferente naturaleza — sociales, personales, organológicas - y propone recursos para ponderar los resultados obtenidos, pero sobre todo arroja luz sobre cómo los planes de estudio y la gestión y producción actuales pueden contribuir a que se atenúen las diferencias de género en los aspectos descritos.

El artículo de la Dra. Coral Morales, de otro lado, profundiza en un aspecto concreto de los abordados por Bonastre. Así, esta especialista traslada la materia de estudio a la formación vocal femenina del Madrid decimonónico, mostrando cómo una de las materias de la educación 'de adorno' podía convertirse en la herramienta y la profesión con la que lograr cierta independencia personal y económica. Morales se centra en el estudio de dos instituciones representativas - el Real Conservatorio Superior de Música y la Escuela Lírico-Dramática-, representativos de una realidad mucho más amplia, de manera que y recorre el ciclo completo de los estudios a los que optaban las mujeres en la España del siglo XIX: el tipo de enseñanza, su función en el sistema educativo y las salidas profesionales. Haciendo uso de abundante documentación y siguiendo una metodología histórico-narrativa, su trabajo muestra que, en el periodo de tiempo estudiado, no había diferencias sustanciales entre hombres y mujeres en la enseñanza del canto lírico, pues se empleaba una metodología similar, pero sí que existía una disparidad a la hora de ejercer la profesión. Ciertamente, aunque las mujeres desarrollaron carreras profesionales en igualdad de condiciones que sus homólogos masculinos — pues la demanda de cantantes para los roles femeninos se imponía-, el desempeño profesional como docentes sí que estuvo condicionado por cuestiones de género: de un lado porque, en el ámbito de la enseñanza oficial, una parte importante de las docentes se vio confinada en el inestable puesto de "repetidora"; de otro, porque las profesoras solo podían impartir sus clases a otras mujeres y, finalmente, porque la publicación de tratados de canto de autoría femenina estuvo seriamente limitado por cuestiones socioculturales.

El camino que muestran estos dos trabajos, entonces, parece claro: el camino transitado por las mujeres en el ámbito de la educación musical ha experimentado una evolución, positiva, desde el siglo XIX hasta la actualidad. Si bien los planes de estudio, en materias como el canto, no han mostrado diferencias en la formación de hombres y mujeres, las desigualdades han existido en otros ámbitos, generalmente vinculados al desempeño profesional y a la consideración social que unos y otras han recibido. Así, resulta evidente que es necesario seguir indagando en los procesos de enseñanza-aprendizaje y proponiendo mejoras en el sistema educativo para que, con políticas eficaces y eficientes, las disparidades por razones de género se disipen definitivamente.

@DESIRÉE GARCIAA-GIL Y CONSUELO PÉREZ-COLODRERO. THE CONTENT OF THIS ARTICLE IS THE SOLE RESPONSIBILITY OF THE AUTHORS. THE REVISTA ELECTRÓNICA DE LEEME AND UNIVERSITAT DE VALĖNCIA ARE NOT LIABLE FOR ANY LEGAL ACTIONS THAT MAY ARISE INVOLVING THE ARTICLE'S CONTENT. REVISTA ELECTRÓNICA DE LEEME -LISTA ELECTRÓNICA EUROPEA DE MÚSICA EN LA EDUCACIÓN-HTTP://OJS.UV.ES/INDEX/PHP/LEEME/INDEX. ISSN: 1575-9563. EDITORES: UNIVERSIDAD DE VALENCIA Y JESÚS TEJADA GIMÉNEZ. VISIBILIDAD DE ESTA REVISTA: SCOPUS, EMERGING SOURCES CITATION INDEX (CLARIVATE), EBSCO, CINDOC (CSIC), CITEFACTOR, COPAC, DIALNET, DICE (CSIC), DOAJ, E-REVISTAS (CSIC), EBSCO PREMIER, ERIH+, GALE CENGAGE LEARNING, IN-RECS, IRESIE, LATINDEX, MIAR, OCLC WORLDCAT, RESH, REDIB, RILM CORE JOURNALS, SUDOC, ULRICHS, ESTA REVISTA ESTÁ PUBLICADA CON EL APOYO INSTITUCIONAL DE REDIRIS-CONSEJO SUPERIOR DE INVESTIGACIONES CIENTIFICAS Y ES DE ACCESO LIBRE. CREATIVE COMMONS LICENSE 4.O BY 